\title{
Turning Immigrants to Citizens: Merits of the pedagogical shift in 3D Virtual Learning Environments
}

\author{
Noha Saleeb, Georgios Dafoulas \\ Middlesex University, London, UK
}

\begin{abstract}
The extent of reliance of current generations of students on information and communication technology (ICT) for education has been a debatable issue for decades. Despite this controversy, there is a generalization amongst researchers that fundamental shifting of educational methods towards e-learning is deemed inevitable and beneficial to cater for students' skills and preferences, through newly emergent 3D Virtual Learning Environments (VLEs) like Second Life. This paper derives and critically analyses, using grounded theory, advantageous themes and their sub-concepts of providing e-learning through 3DVLEs.Furthermore it discusses two identified states of learners in 3DVLEs, namely digital natives and digital immigrants, and how these pave the way for emergence of digital citizens in 3DVLEs.
\end{abstract}

\section{Introduction}

This paper examines early ideas presented in our previous endeavor, on first introducing the concept of pedagogical immigration to 3D Virtual Worlds. We claimed that technology savvy generation should have the right to declare themselves as 'natives' of 3DVLEs. We assumed that their experience with video games, Internet access, Web 2.0 tools and social networks provides them with sufficient behavioural patterns and habits to fit in any 3DVLE. After sufficient time and several pilot studies, experiments in 3DVLE learning scenarios, we are confident that we were not entirely right but also far from being wrong.

On one hand, there is indeed a generation that possesses far more technical skills and ability to orient itself in a virtual world. The interface features and usability experience are not entirely strange to affect the way they operate in the environment. On the other hand, the virtual world concept is not one that they have associated with a teaching and learning setting. In that sense when we introduced 3DVLEs to our subjects, we experienced something unique. The tribe of 'natives' that were our students did not lead the way entirely and needed us, the 'pedagogical immigrants' to help them find the true scope of the 3DVLE.
We are therefore ready to enhance our initial contribution by defining a new scope for our work. Using the same analogy, we could claim that we are both, students and instructors, together in a period of familiarisation. It is no longer a case for immigrating our physical world pedagogy into an entirely new world. It feels more likely that we were welcomed to the new land, the environment seems to be appreciative of what we have to offer in terms of design and delivery of IT enabled learning environments. We are indeed allowed to enter a process of naturalization. This means that the next steps are to establish ground rules for a 3DVLE education. We are no longer trying to make our existing practices fit to the new environment but offer a truly innovative and unique way of experiencing education. A new educational era is emerging; it is one that requires some technical expertise to handle but in return offers the opportunity to become 3D world citizens.

Online 3DVLEs have been a host, since their offset, for hundreds of virtual university campuses. These offer e-learning opportunities for numerous diversities of students in many fields including science, medicine, engineering, business, law, computer-science, humanities etc. This has reaped noticeable participation, satisfaction and hence achievement from students [1]. It thus becomes imperative to extract, analytically, the merits and drawbacks of migrating with delivery of e-learning to these environments.

The emergence of digitally influenced generations of students, whom Oblinger and Oblinger [2] refer to as "Digital Natives, "Games Generation" and "Millenials", deems it logical to expect that in order to enhance future learning, students will be encouraged to utilise game-like 3D virtual worlds, or VLEs like Second Life, to accommodate for new cognitive style changes. These play an essential role in shaping future e-learning since “Today's students are no longer the people our educational system was designed to teach” [3].

\section{Research rationale}

All The fundamental concept of Grounded Theory as founded by Glaser and Strauss [4] denotes that research, starting with no predetermined hypothesis or theory, can ultimately generate one by 
analysing primary data sources, (from qualitative empirical data, existing literature or any kind of data [5]), where the unit of analysis is an incident. From many incidents, a series of key points can be extracted which are then marked with "codes". These in turn are grouped into "concepts”, and from related concepts emerge main "categories" (or themes) [4]. Within this study, our raw source of data (or incidents) was documented literature depicting case studies of Second Life usage (immigration) by a multitude of educational institutions for e-learning in its various forms. Key points, each representing a possible advantage or disadvantage for delivering elearning in VLEs, were inferred from each documented incident and grouped into three main clusters of codes:

1- Those supporting traditional physical education,

2- Those unavailable in and adding to capabilities of 2DVLEs, and

3- Those unavailable in physical classroom learning.

Components of each code cluster were then named as 70 concepts, which were in turn grouped into 16 advantageous and disadvantageous categories (themes). A final general hypothesis was formulated resulting from the emerging categories (themes). The low level individually-mined key points are not included in this paper. The paper provides, a description of each theme and its sub-concepts, formulated from the key points, showing the division of these concepts into the three coding clusters mentioned above.

The authors believe that the three coding clusters summarise current practices and research objectives in the field. The motivation for clustering the literature evidence was to supply a mapping of currently disjointed efforts in the field. Underlying themes in current work, on one hand, lead towards using 3DVLEs as supporting tools for traditional education along other applications; on the other hand push towards defining a new generation of e-learning shifting away from what was previously known as a VLE, exploiting the game acquainted generations.

The arguments supported in this paper are based on a number of pilot studies that concluded to the identified participant behaviours. The underlying aim of the research was to focus on both learning and architectural requirements of virtual worlds. However the emergent concept of digital citizens has helped to add yet another dimension in the work that was carried out. The primary data collected included the following:

- A study of 3DVLEs supporting learning settings in established institutions worldwide, focusing on the architectural features and learning aids used.
- A study on how learning was achieved in a 3DVLE with the delivery of various types of learning activities, including seminar, lab sessions, discussions and lectures,

- That allowed the participation and exchange of ideas between digital immigrants undertaking the role of digital natives.

- A study on the assessment results and feedback provision of participants who used the 3DVLE to construct their knowledge

- A study on overall experience of participants based on their communication patterns and observation of their avatar movements and behaviour.

- A study based on comparative analysis between uses of 3DVLEs in different Universities to support various learning scenarios.

The above list of studies is indicative of the wealth of primary data that have been analysed in a number of different contexts. The main contribution for this paper is in the form of a list of advantageous themes that may lead towards obtaining digital citizenship in 3DVLEs.

\section{Turning immigrants to citizens}

As mentioned in the former introductory section, the authors aimed at identifying factors that determine behaviour of digital natives, immigrants and citizens in virtual worlds. We could therefore identify that participants in 3DVLEs may belong to either (i) digital natives or (ii) digital immigrants.

Digital natives are usually those with the technology skills that have been acquired during an extended period of familiarisation with virtual world technologies. A typical assumption is that students are the predominant members of the digital natives grouping. A generation subjected to online games and virtual environments is likely to show such behaviour.

Digital immigrants are those with the lack of technical skills but an awareness of the academic context within which a virtual world should operate in order to become a successful 3DVLE. A typical scenario is for academics to naturally belong to this grouping as their objective is establishing a pedagogic foundation to be enhanced with the aid of new technologies.

It is imperative to understand that there will always be academics who belong to digital natives as they may be experienced in using innovative solutions for teaching and learning practices. Conversely, background of students may include awareness of learning styles and pedagogy but lack the technical background that would classify them under digital natives. 


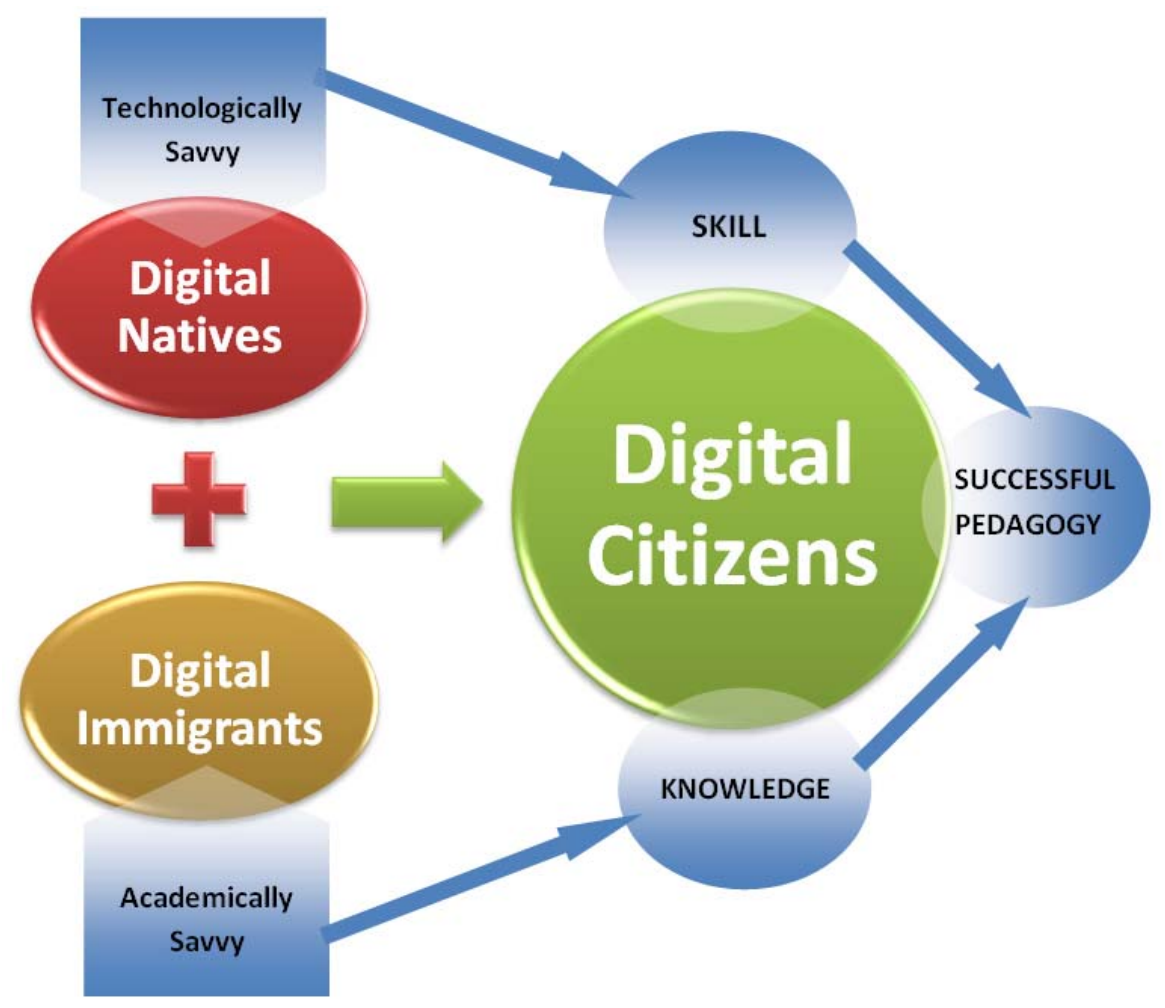

Figure 1. Transition from Immigrant and Native states to Digital Citizen State

As shown in figure 1, transition from the two states discussed above requires acquisition of certain skills and knowledge that enables participants in 3DVLEs becoming digital citizens. By ensuring that learners have become digital citizens we may argue that we established a successful pedagogy for the emergent medium.

The above perspective is very useful in providing a conceptual model of how different behaviours of user types may be determined. Data analysis of primary data collected from the pilot studies performed in earlier stages of this research allowed observing in depth learners' behavioural patterns. A key decision affecting primary data value was to include video recordings of avatar movements and snapshot capturing while learning activities were taking place. The importance of maintaining such video and image diaries was critical to assess how avatar behaviour reflected on learner behaviour. Additionally, recording actual movements of learners while using computers in labs and seminar rooms was used to correlate the way avatar behaviour corresponded to each participant's behaviour.

This practice provided sufficient evidence, leading to coining the terms natives, immigrants and citizens for the avatars behaving on behalf of their learner controllers. This section includes a number of snapshots (as video segments are impossible to include) describing typical behaviour for each one of the avatar types.
As mentioned earlier, digital natives were regarded as technology savvy and able to use the virtual world without major obstacles. During learning activities, the natives showed remarkable variations in the way their avatars were behaving. It was evident that the navigation and movement issues associated with early induction on virtual worlds were not affecting their use of the system. The personalisation of avatar appearance and acquisition of tools, scripts and various types of objects were constantly affecting their behaviour. There was no consistent pattern for their presence in the virtual classrooms as they were able to alter their viewpoints, move their avatars around and even fly out of the dedicated space, exploring the island while engaging in voice and chat communication. Digital natives were the best when using objects provided in the virtual space but lacked the concentration required for learning activities. They were not used to this kind of space to be used for a learning setting.

Digital immigrants were on the other hand too focused on the learning task and failed to become familiar with the space on their own initiative. It was very interesting to observe that they followed the same path based on given instructions during their induction and orientation stages. They gradually became aware of different functionalities and some basic features of the virtual world. However, their focus on the learning scenario meant that they did not explore the full range of aspects available in the 3DVLE. 


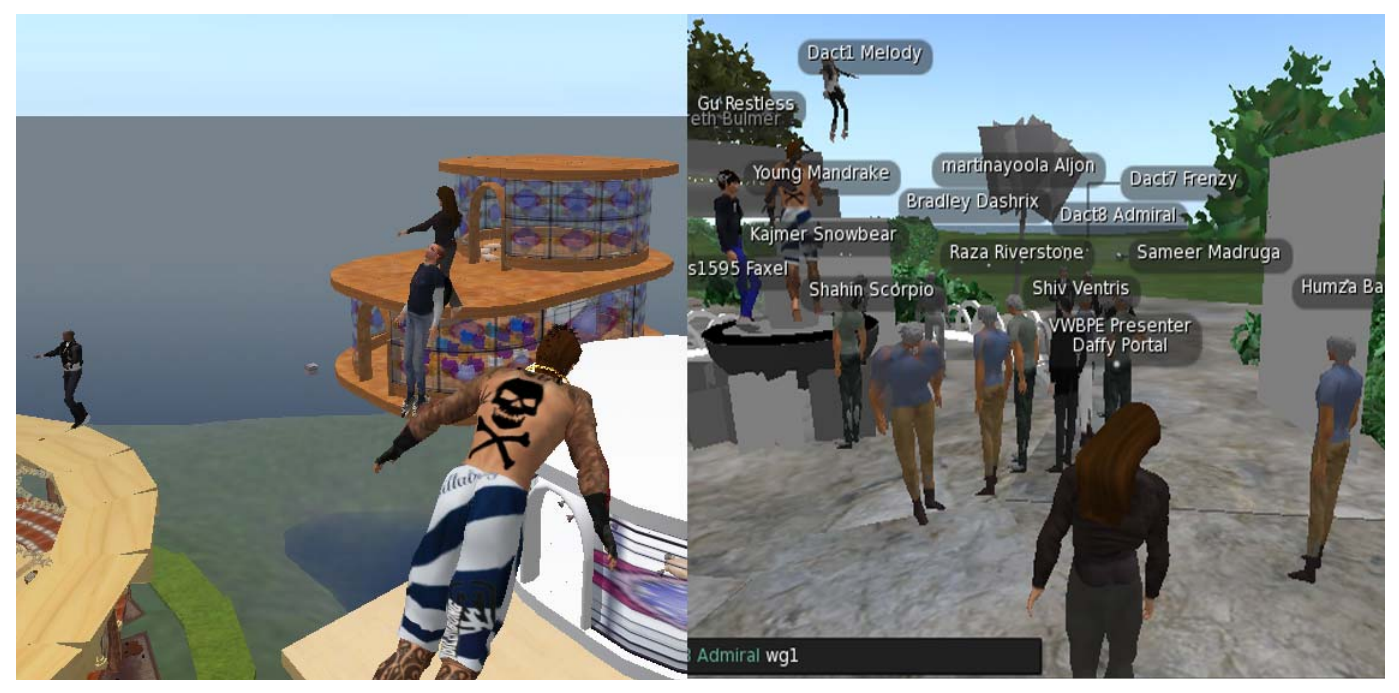

Figure 2. Activity behaviour of digital natives

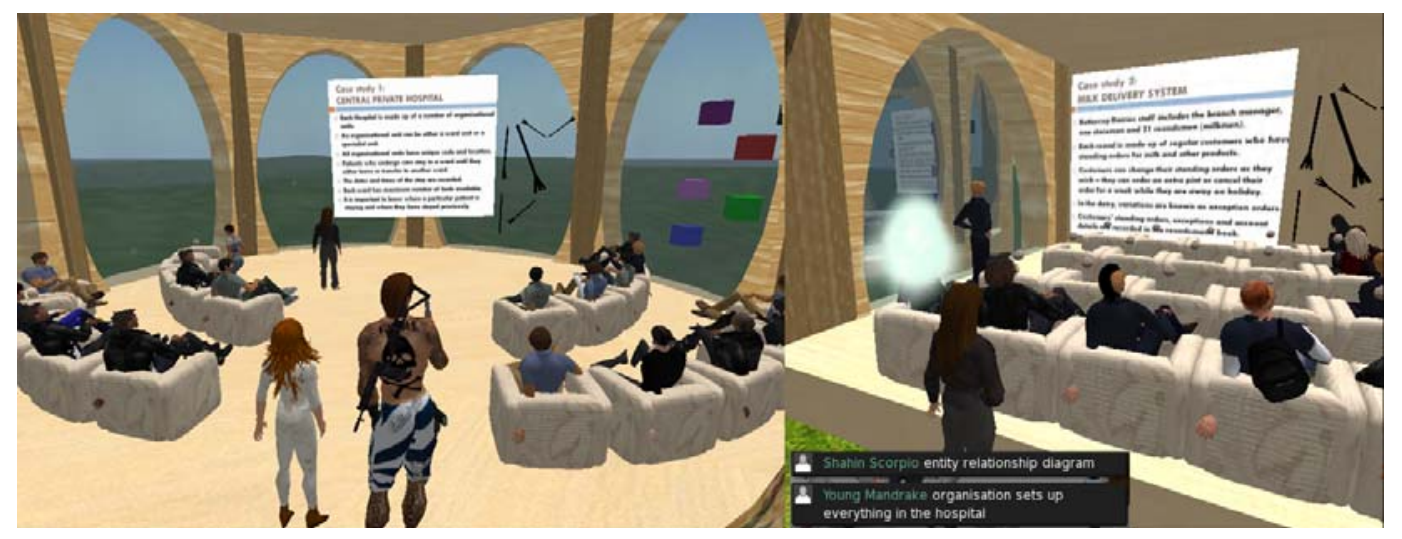

Figure 3. Activity behaviour of digital immigrants

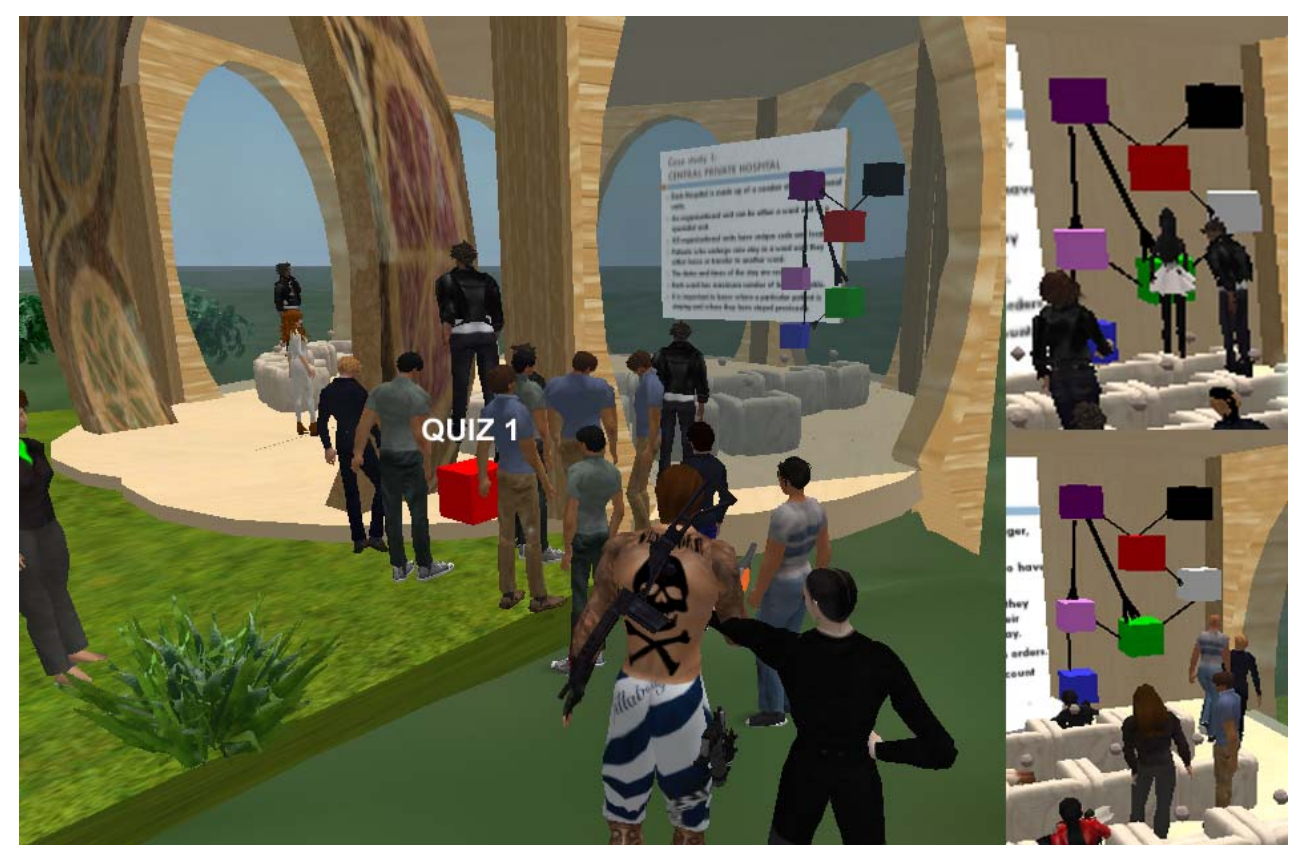

Figure 4. Activity behaviour of digital citizens 
For example, as shown in figure 3, the focus of their participation was the learning content. This meant that they tried using the seating provided, face the projecting boards and slide-shows and engage in constructed discussion with instructors. Their avatars remained immobile in most cases perceiving that they should reflect the behaviour of humans when attending a learning session. It was impressive to observe the dramatic change when digital immigrants attended same sessions with digital natives. It was easy to distinguish the two groups based on the way their avatars moved through the space. However, there was an aspect of digital immigrant learning that enabled their avatar mobility. When tasks required their joined design efforts, avatar movement was then perceived as an integral part of the learning activity and they immediately became active.

Figure 4 shows evidence of the gradual effort of both digital natives and immigrants becoming digital citizens of the 3DVLE. Once the technology required is no longer a differentiating factor, the foundation required for digital native behaviour to be apparent is no longer there. After a series of three to five sessions almost all participants expressed behaviour necessary for users to be viewed as digital natives. The same familiarisation period was sufficient for certain aspects of digital immigration of the learning context to become evident among all participants. Digital citizens are learners who have no difficulty in using the virtual world tools to allow their avatars engaging in learning activities. Digital citizens are also learners capable of identifying what is required by each learning activity supported in the virtual world. More importantly, digital citizens are learners who efficiently communicate with other participants.

It should be noted that the authors' view on digital citizenship is that it affects both instructors and learners. This paper argues that the emergent paradigm involves instructors and learners in a collaborating relationship. The notion of digital citizenship relates to the creation of a learning experience based on possession of key skills and expression of certain types of learning behaviour.

\section{Advantageous themes of $3 D$ virtual learning environments - towards digital citizenship}

The following thirteen categories are high level advantageous themes of delivering e-learning within 3DVLEs, derived using the method described earlier.

\subsection{Involvement}

In the context of this paper, involvement can be defined as student participation, interaction and contribution during a 3DVLE e-learning session, comprising the subsequent concepts:

Active student roles

New roles emerge as students move from physical campus or online discussion boards to virtual world classrooms. Learning centres on discovery, hence shifting students from passive roles of survivors and castaways in space-confined physical classrooms to the active roles of researchers can be done in 3DVLEs [1].

Object ownership

Ability to buy or freely possess personalised accessories, buildings, gadgets etc. in each user's individual "in-world" inventory, gives a feeling of belonging, loyalty to the virtual world, and will to return back again and resume activity within the environment [6].

The Second Life (SL) Design Competition organized by Massachusetts Institute of Technology for students to design their own spaces for learning and residence, to interact and connect with others, is an example of enforcing active student roles and object ownership [7]. This requires minimal foreknowledge of how to build and create.

\section{Embodiment}

Embodiment of the user as an avatar and ability to renovate its shape, skin and style, can transform the sentiment towards the space of a virtual world into a sense of belonging to the place [8].

Sense of presence

Ability to communicate, add face gestures and body movements to the avatar, adds to the sense of presence within the scene [6].

For example, media students at Trinity University San Antonio implement promotional campaigns in SL utilizing these avatar functionalities to advertise [9].

- Native behaviour - usually in the form of behaviour types that include the learners to create objects relevant to learning tasks. Interaction of natives with the learning environment may also include usage of notice boards, slideshows and web content.

- Immigrant expectations - including the presence in learning scenarios either as participants to communication or by further actions that may require manipulation of objects.

- Citizen responsibilities - they are likely to participate in learning activities including voting, tests, discussions and Q\&A.

\subsection{Activities}

Positive actions and activities undertaken by students in 3DVLEs can be categorised into the following concepts: 
Experimentation:

The virtual world opens up opportunities not offered in the physical world, e.g. experimentation with simulated science experiments, space phenomena, studying minute biological entities or chemical reactions enlarged.

Exploration:

This includes exploring new ideas impossible or too dangerous to approach in reality like nuclear explosions [8].

Johnson \& Wales University demonstrates these concepts through BLAST, a scientific ballooning project in SL dedicated to understanding universe origins. Students and scientists collaborate in designing the balloon [10].

- Native behaviour - it is typical to interact with the surroundings and the learning environment, often affecting learning focus.

- Immigrant expectations - focus is primarily on transferring activities from traditional learning context to virtual worlds, meaning that usage of the $3 \mathrm{D}$ environment is customised to fit the learning needs.

- Citizen responsibilities - the alignment of learning tasks to what the 3DVLE offers is the aim for setting up successful learning activities.

\subsection{Existence}

The nature of presence as a user in 3DVLEs varies completely from real-life, enriching the elearning process via the following concept: Distributed/ co-present existence

3DVLEs enable immersion by being inhabited by users, who are themselves both distributed (their physical bodies are spread out all over the world) and co-present (their avatars are in the same space) [11].

- Native behaviour -existence of natives in virtual worlds is irrelevant to the learning task as their presence is part of their typical use of virtual worlds.

- Immigrant expectations - their presence in 3DVLEs is frequently mapping out their presence in the real world and the avatar behaviour usually resembles the way interactions take place in real-life. It is not expected for the avatar to exist after the learning activity is complete.

- Citizen responsibilities - any learning activities are only part of the avatar existence that reflects the $3 \mathrm{D}$ virtual presence of the user and not just the tool used for accessing a learning environment.

\subsection{Communication}

Contact methods during e-learning sessions between students, teachers and transportation between locations, are innovative within 3DVLEs, characterised by the consequent concepts:

\section{Public and private messaging}

Students can communicate via text, voice, ask confidentially whenever they please without interrupting others- by corresponding with classmates or teacher via private messaging channels, thus overcoming shyness [1]. This is essential in interactive courses e.g. conducted by Bradley University to coach students in qualitative research methodology.

Teleporting

Teleporting can be done instantaneously between different 3D sites, e.g. representations of historical simulations like "Paris 1900" in SL [8]. A successful example introduced by Johnson and Wales University was creating "virtual Morocco", an immersive experience about Moroccan culture [10]. Alternative communication support

There are also benefits from using alternative communication support via voice in the virtual world, voice over IP, or by means of a conferencing tool [12].

\section{Ease of guest lecturing}

Guest speakers can be invited to attend sessions virtually without their actual physical presence.

- Native behaviour - the technology savvy user is able to communicate using voice, text and instant messaging. The use of Web 2.0 tools ensures that the communication is achieved in many different ways.

- Immigrant expectations - the primary communication tool is the main chat facility and usually switching between communication modes may pose an obstacle to the smooth use of the environment.

- Citizen responsibilities - the aim is to achieve a communication with other participants that does not affect the navigation of the avatar or the participation to any learning activities.

\subsection{Educational Aids}

Additional methods and objects are available within 3DVLEs to assist delivery of e-learning including the ensuing concepts:

\section{Ease of snapshots}

Simplicity of recording pictures/ snapshots within 3DVLES allows for future reference to events in lectures and workshops etc.

For example University of Kansas hosted an online International Media festival in SL featuring works by art students around the globe, with live interactive lectures. These events required extensive imagery recording as form of documentation [13]. Cheap file upload 
This is available for presentations, images etc. requiring inexpensive payment per file for usage within a 3DVLE.

Streaming music

An option used by instructors during live lectures unlike in 2DVLEs.

Presentations on 3D objects

Furthermore, PowerPoint presentations and streaming videos can be placed on cubical objects and presented to students in a more interesting manner than 2D environments. Professors from Texas A\&M University upload students' work, streaming video, written projects to conduct SL classes, provide tutorials, assign projects and achieve research related to digital visual culture.

Sandboxes to practice building

Students and instructors use these freely in 3DVLEs [8]. Students from Colorado Technical University learned basic virtual world building and texturing skills, developed user-interface prototypes, designed usability experiments, and conducted usability evaluations in SL. The virtual world classroom became an open space version of a usability lab.

$\underline{\text { Session message logs }}$

Instant messages can be saved as logs for future reference of lectures.

\section{D learning stations and objects}

Learning stations "in-world" can be designed to provide content to students who are absent or need extra time to study and reflect. Students can take notecards by touching 3D objects, listen to podcasts, or watch streaming video covering lesson material. Although this ability is also obtainable in online course management systems (2DVLEs), the shared nature of an avatar interacting with an object and seeing 3D simulations of the content come to life, is more powerful [1].

This is exemplified in stations offered by Texas A\&M University for students to receive assignments written on notecards along paths on the SL campus [9].

Supporting all learning styles

Some people learn best by listening to course content, others by seeing and visualizing, and some using a hands-on approach. In 3DVLEs, a mix of content and activity supports all learning styles: auditory, visual, and kinaesthetic.

Online assignment submission

Students can submit assignments in the form of notecards easily to teacher by dropping it over his avatar or profile.

Program execution in linden language

Submission of program assignments can be done in SL Linden scripting language (LSL) to see the program run directly in the environment and working. The advantage is that LSL is easy to learn for its similarity to other programming languages e.g. Java [14].
University of Florida students, for example, created 3D programs using LSL, Java, Python and Lisp [10].

3D architectural assignments

These may be submitted in a virtual environment as $3 \mathrm{D}$ models that can be rotated around or entered inside [1]. University of Colorado architecture students design buildings and create structures, using built-in tools to construct their ideas as a form of virtual sketching. These 3D objects offer context for discussion during class projects [9].

Engagement in real world issues

Experience of University of South Australia students interacting with their clients through SL provides insight into the real world through virtual work encounters i.e. by experiential learning [15]. Furthermore Texas A\&M University engages students in SL with significant questions about reallife and virtual associations [9].

- Native behaviour - it is quite common for typical users to have a customised interface setting that is based on their key preferences. This may include use of music, manipulation of objects, inventories and teleport locations. Use of learning tools is expected similarly to other interacting tools that exist in various locations.

- Immigrant expectations -use of certain learning tools must be described in detail and a learning curve is associated with each different tool used. Introduction of such tools resembles the way VLEs enhanced traditional teaching styles and evolved as an additional medium to the face-to-face learning style.

- Citizen responsibilities -use of learning aids should be decided by assessing the learning needs and establishing an understanding of how to best meet the requirements of learners and exploit capabilities of instructors.

\subsection{Interaction}

Additionally, different types of networking options between users are offered in 3DVLEs, characterised by the following concepts:

Social spaces

Social spaces existing within 3DVLEs provide successful shared communities. These are also cultural spaces providing opportunities to truly engage and communicate with others to learn about different customs, behaviours and ethnicities [8].

Hong Kong Polytechnic University uses SL to help 1st year students get acquainted with university life and adjust to transitioning from high school, offering a variety of interpersonal, learning and selfmanagement ideas to help excel in their undergraduate life.

Networks of distant users 
These can be created for sharing of skills and knowledge through blogs, wikis and knowledge repositories that can be opened within 3DVLE windows during active e-learning sessions.

These can develop and enlarge with time to include different background users or collaborative universities [16].

Instructor role shift

In virtual worlds, the instructor's role shifts from being focus of attention to being domain specialist or facilitator who motivates and manages discovery while providing organization, guidance, feedback, and assessment [1].

A successful implementation at Harvard University (Law School) involved building a court room in SL for students to practice their advocacy skills, without intimidation from similar real-life spaces. Under professor supervision, simulations of trials were conducted in SL, weekly office hours held in SL to discuss material and homework with teachers, and socialization with classmates \& faculty [7].

- Native behaviour - it is expected that regular participants belong to extensive networks of users that exceed the members of a course. Use of such networks to obtain information and support may provide opportunities not present in traditional settings where learners have the sense of belonging for their immediate cohort.

- Immigrant expectations - interaction is usually constrained in the form of immediate communication to other present members and instructors. Asynchronous communication is not preferred and interaction does not continue after learning sessions are over.

- Citizen responsibilities -need for interaction should be classified according to the learning scenario and 3DVLE supporting each session. The learner should be able to decide on different modes of interaction depending on how they can support specific learning activities.

\subsection{Security}

User identity protection and account safety are vital issues within 3DVLEs, as demonstrated by the following concepts:

Anonymity safety

Sense of safety through anonymity of users' identities can encourage students to experiment in ways not possible offline [8].

Username \& password

Requirement of access permissions is similar in 2D and 3DVLEs. Both environments necessitate authorisation of participants in the form of a name and password. Furthermore, each educational institution can restrict usage of its premises within a
3DVLE to only specified lists of students thus ensuring security [6].

\section{Free registration}

Free registration to 3DVLEs is available for normal users e.g. students. Premium (paid) access is only for organizations like universities to purchase lands and build their personalized virtual campuses [16], e.g. Oxford University's virtual First World War Poetry Digital Archive inside SL dedicated to commemorating this period's classical works and poems, including audio, video interactive tools and tutorials for students [17].

- Native behaviour - being able to identify the typical dangers associated with the communication in a virtual world means that digital natives are rarely affected by security issues.

- Immigrant expectations - the novice stage each digital immigrant must go through during early learning sessions could be compared to early sessions of familiarisation when accessing the World Wide Web.

- Citizen responsibilities - awareness of any dangers and identification of key security issues is key for establishing a safe and secure presence in 3DVLEs.

\subsection{Output}

Degree of productivity of courses within 3DVLEs can be assessed through the following concepts:

Immediate instructor feedback

Such feedback within the synchronous class experience in 3DVLEs allows for engaging interaction and expression while drafting ideas and conducting activities [1].

Early assessment of course

Such assessment can be performed by students since the learning process and measurement instruments are observable. This allows immediate in-course enhancement and spending less time in critically assessing a course after it ends [1], e.g. Management School at Edinburgh University UK, relies heavily on instructor feedback and assessment issues for its MBA courses in SL [7].

- Native behaviour - feedback is usually obtained in the form of unstructured and informal communication. Although this seems sufficient for regular users, it may prove difficult to associate it with specific learning activities and reflect on performance.

- Immigrant expectations -traditional methods for receiving and discussing feedback mean that certain forms of feedback may not be perceived as acceptable. 
- Citizen responsibilities - being able to distinguish which forms of feedback and output are the most suitable for the different learning tasks being supported.

\subsection{Educational Strategies}

3DVLEs can provide innovative instructional techniques, methods or archetypes for facilitating learning [18] including:

\section{Classroom emulation}

Such emulation allows for re-creation of the physical classroom environment within the 3D world. Advantage of this method is achieving familiarity with the virtual space because of its analogy with the real-life space, as observed by the immersion experience of Texas A\&M University in $\mathrm{SL}$, teaching reading competency in reality depicted learning spaces [9].

Game based learning - treasure, scavenger hunt

With little time and large curricula to cover, one way to realize effective learning is using game-based techniques to pique students' interest especially with the resemblance in appearance of 3DVLEs with game settings [1]. Examples include treasure or scavenger hunts which provide opportunities to explore areas. This could e.g. be used to orient students with campus layout [18]. A software design class from Colorado Technical University, for example, created a 3D game maze and populated it with traps, sensors, flags, a scoreboard, treasures, and other game features, then played it as a form of testing. These students were so immersed in the learning experience they accomplished goals of several classes in one [1].

Role play

Enacting or assuming an alternate character to oneself is a widely employed learning technique which can also occur virtually within 3DVLEs. This virtuality might remove some of the traditional hindrances of performing face-to-face role plays, e.g. by easily dressing avatars in a variety of clothes, easily incarnating imaginary settings, not being shy to participate. This enhances learning because students are encouraged to use all their skills and abilities to impersonate the role play presented to them [18]. One example of literature class role-play is enacting the courtroom scene from John Steinbeck’s “Of Mice and Men” [1].

\section{Guided Tours}

Such tours are used to show learners in a 3D synchronous environment location of items and features within an area. A tour can be led by instructors or using a pre-programmed item the avatar carries that takes him on a virtual "guided tour" without need for a live person. E.g. country or historical building tour, battle fields or forts, a tour inside a blood capillary or volcano where the learners are diminished in size to experience areas otherwise unreachable [18], like project "Virtual Morocco" created by Johnson and Wales University [10].

\section{Conceptual Orienting}

Learning to create plans, e.g. for business, entails providing students with examples and non-examples of a concept, allowing students to perform side-byside contrast, and identify attributes that do and do not apply to the concept. [18]. For example, University of Houston architecture students build business plans in SL and subject their models to forces of SL's free market [9].

Operational Application

This is "learning by doing" in the virtual environment. Students follow regulations and constraints of the physical world to perform tasks. Facilitators monitor students and make remarks or commendations, e.g. fixing equipment, troubleshooting a computer network, performing a virtual experiment or repairing a car.

\section{Joint Co-Creation}

This occurs when groups collaboratively craft items within the 3D world. This procedure teaches teamwork, cooperation shedding light on benefits and pitfalls of group-work [18].

An innovative group-work approach by University of London and Kingston University presents paramedic students with critical patient emergency scenarios on the streets "in-world". The students then collaborate in synchronous teams taking rapid decisions to check a dummy avatar's vital signs e.g. pulse, apply treatment e.g. dressing wounds, oxygen masks, administering drugs, setting GPS in ambulance etc. Their submitted reports in virtual hospital are mailed to their real-life instructor. This educational approach solves the problem of rarity of critical cases in reality to practice on, and relieves stress from risk of trying out incorrect remedial techniques in reality [19].

\section{Critical Incident involvement}

Students are positioned into a virtual predicament analogous to a real situation. Students then use former knowledge to resolve the problem; for example being placed into heart of disasters like hurricanes, earthquakes, car accidents or blazing buildings [18].

\section{Practical training}

University of Kansas teaches medical and nurse training in SL, e.g. dealing with different equipment, studying patient anatomy and attaching devices to them. Moreover, physical therapy students use SL simulations to evaluate handicap hazards in virtual homes, recommend improvements and apply changes. [19].

- Native behaviour -ability to follow different scenarios and role playing means that avatar presence, behaviour and interaction is adapted accordingly. 
- Immigrant expectations - there is reluctance to follow unstructured learning processes with requirements for specific guidelines to be followed.

- Citizen responsibilities - use of 3DVLEs does not require different skills to everyday life. As in reallife, a learning mode is entered when a learning session begins, similarly an avatar should enter each learning activity based on the educational strategy used.

\subsection{Performance}

Speed, efficiency, quality of technical connectivity and delivery issues online while using 3DVLEs for e-learning are palpable through the following concepts: Faster MONO virtual machine

SL for example currently uses the Mono Virtual Machine (VM). Executing on the Mono VM gives up to 220 times speed increase, reduced lag and improved stability [14].

Dot-net languages' support

An additional benefit is that any dot-net language that compiles to the Mono VM can be uploaded to execute in SL. This enables student programs to execute immediately for instructors on submission [14].

- Native behaviour - typical users are aware of any technical issues affecting the performance of the system and are able to assess any impacts to a learning experience.

- Immigrant expectations - it is highly unlikely for novice users to be aware of when a learning experience is affected by technical issues.

- Citizen responsibilities -ability to alter learning expectations based on the technology infrastructure means that the most suitable tools are used for each learning session.

\subsection{Setting}

Importance of the surrounding environmental arrangement and background settings of the spaces, where educational sessions are held within 3DVLEs, constitutes the following concepts:

Untraditional class settings

Includes non-confinement to having chairs facing forwards, allowing free movement within the learning environment, sitting in any position without affecting the view [12]. Examples of untraditional classrooms are on display within the Art Department, University of Kansas virtual campus, featuring a lecture hall, open air studios, interactive gallery of sculpture etc.

Easy class management

Fewer problems arise from noisy interruptions of students since communication is either text-based in
3DVLEs or even with audio transmissions, only one person can talk on the system at a time. Instructors can also block or remove inappropriately behaving students.

\subsection{Perspective}

The viewpoint and angles of perception of users within a virtual 3D space are essential factors denoted by the consequent concepts:

Customisation and conceptual imagination of avatar

As mentioned before, avatar personalised representation in the virtual world allows for the user's identification with it. Conceptual blending also provides further imaginative insight e.g. using talking animal avatars. One can change avatar gender, race, and even species [8].

Colorado Technical University students commented that "the sense of presence and customization of avatars are high on the list of priorities for learning and participating in virtual world classes”, despite spending considerable time modifying their avatars and perfecting communication, expressing emotion and gesturing [1].

Virtual reality versus virtual world view

The option of changing between virtual reality view (in 1st person by looking through avatar eyes within the environment) or as a virtual world view (in 3rd person by watching the avatar move) can change the feeling of immersion in the environment [12].

Adjusting cameras and lighting

This can be done by adjusting cameras/ lighting etc within the 3D environment to change the angle of perception of the real user within the 3DVLE despite the position and direction of the avatar [20].

Day and night settings

These can be customised within a 3DVLE according to users' preferences e.g. dusk, dawn, midday, to help learn in personalised comfortable surroundings [6]

An example is the University of Texas students' visit inside enlarged replicas of Vincent van Gogh's Starry Night, and the cave paintings in Lascaux.

Attractive 3D graphical setting

The dominant content form of a 3DVLE is imagery thus making it an image-based environment which is attractive and vivid for users [6].

Viewing and hearing from any position

Viewing and hearing any part of the learning space from any angle with clarity, regardless of the avatar position (even if seated behind the lecturer), eliminates the need, like in real-life, to sit near an instructor or find acoustic solutions for hearing a lecture [12]

Buffalo State College fashion design students [19] for example host fashion shows in SL without 
worrying about positioning all spectator avatars near the runway for proper viewing.

\subsection{Locations}

Imaginary, dangerous, historical or unreachable places

Students can examine and explore a variety of imaginary or difficult to reach places in reality e.g. on the top of mountains, in outer space, bottom of ocean, representations of historic or extinct civilizations, travelling between continents during the same session thus saving time and money to do so in reality, etc [8]. Texas University, for example, holds classes on a SL tropical island [9].

\section{Teaching and Learning} considerations

In this paper we have discussed the three concepts of digital natives, immigrants and citizens. These terms may well describe the different states of a learning paradigm applicable to 3DVLEs. As formerly explained, each state has a number of advantageous themes affecting the way its members behave. However as seen in figure 5, some themes are related more closely to a specific state.
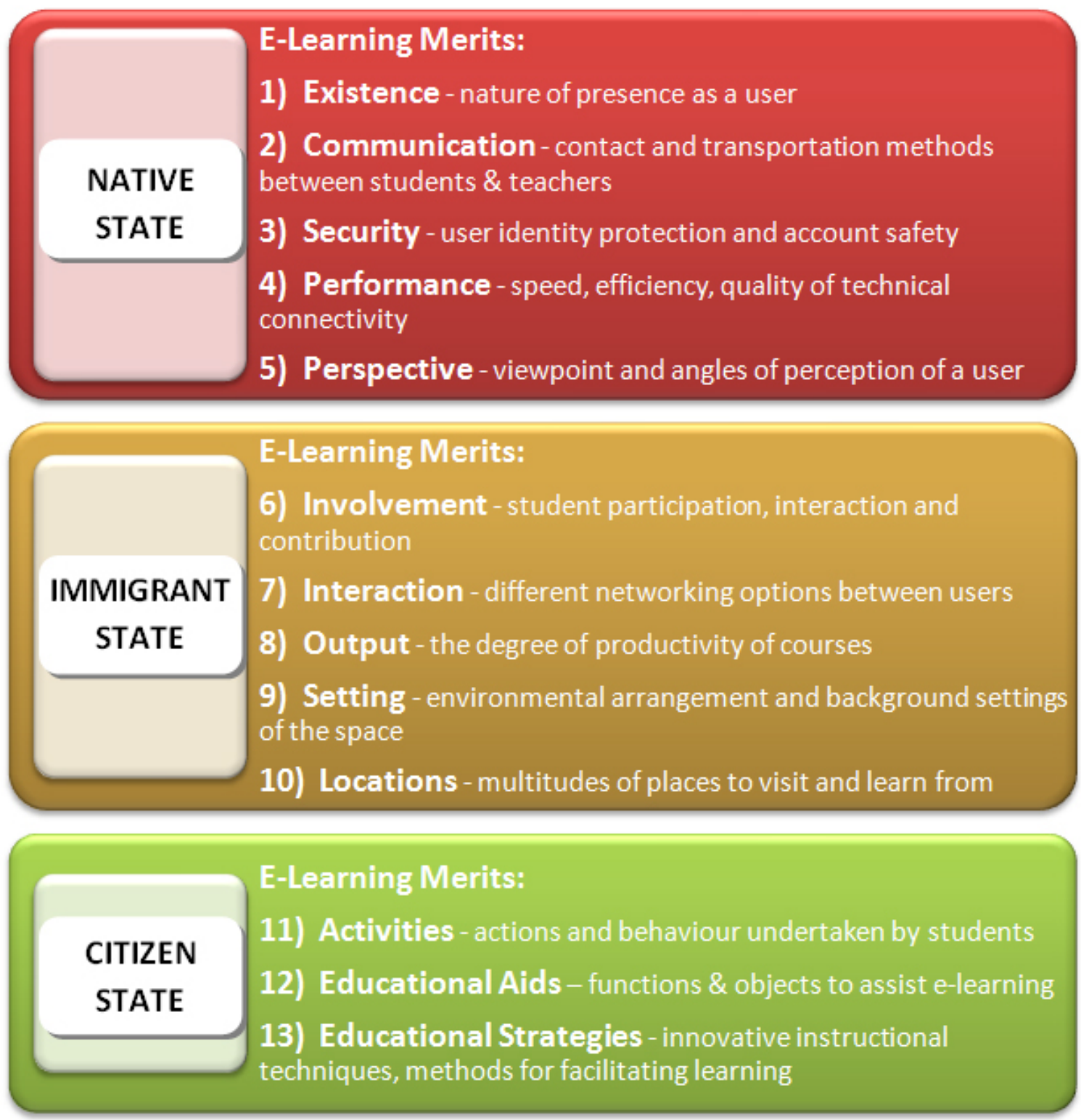

Figure 5. Advantageous themes of e-learning in 3D virtual learning environments 
The native state focuses mainly on (i) existence, (ii) communication, (iii) security, (iv) performance and (v) perspective. More specifically, digital natives are familiar with the technology and how an avatar demonstrates the existence of a user in the virtual world. Security and performance issues in terms of how technology affects the use of the tools are not a major obstacle and users are capable to optimise their sessions. The way natives communicate is not dependent on the learning session but on the style they adopt to communicate through their avatar. Eventually avatars behave following norms that learners have adopted as users of the 3DVLE.

The immigrant state focuses mainly on (i) involvement, (ii) interaction, (iii) output, (iv) setting and (v) location. The concept of involvement and participation is key for these learners as they are affected by the learning activity they participate in. As there is no underlying pattern of use for such environments, their interaction depends on how they perceive virtual worlds as the medium used for interaction as well as setting for learning sessions. Location and output are two major issues for natives as they affect the way a learning session takes place and participants' learning experience.

The citizen state focuses mainly on (i) activities, (ii) educational aids and (iii) educational strategies. The focus of citizens is neither the learning session nor the tools used. Emphasis is given on activities as they integrate the technology and academic elements of learning experiences. Establishing a framework for assessing suitability and impact of learning strategies and aids to use, is in the core of citizens' concerns.

\section{Conclusion}

This paper aimed to derive analytically, using grounded theory research methods, thirteen advantageous categories (themes) and sub concepts of using 3D virtual learning environments, such as Second Life, for conducting e-learning within them. Hence also prove that the advantages support traditional physical learning techniques, provide more options for delivering education than traditional classroom methods and also more options than those provided by 2DVLEs such as blackboard. It is therefore clear that pedagogical immigration of educators to 3DVLEs can reap more virtues than drawbacks if utilised efficiently.

The paper focused on identifying how the various advantageous themes may help to establish a way to support the alignment between digital natives with their technical ability to operate in virtual worlds and the digital immigrants and their academic perspective of the learning process. The paper attempted to pave the way towards digital citizenship in $3 \mathrm{D}$ virtual learning worlds through the classification of different priorities that may exist in each one of the three possible states.

\section{References}

[1] C.M.Calongne,"Educational Frontiers:Learning in a Virtual World”,EDUCAUSE Review,vol.43,no.5,2008.

[2] D.Oblinger,J.Oblinger,"Is it age or IT:first steps towards understanding the net generation”,In D.Oblinger \& J.Oblinger (Eds),Educating the Net generation Boulder,CO: EDUCAUSE,2005,pp.2.1-2.20.

[3] M.Prenksy, “Digital natives, digital immigrants”, On the Horizon,vol.9,no.5,2001,pp.1-6.

[4] B.G.Glaser,"Emergence vs Forcing:Basics of Grounded Theory”,Mill Valley,CA,Sociology Press,1992

[5] B.G.Glaser,"The Grounded Theory Perspective: Conceptualization Contrasted with Description”,Mill Valley,Ca:Sociology Press,2001.

[6] S.Robbins, “A Futurist's View of Second Life Education:A Developing Taxonomy of Digital Spaces”,Second Life Education Workshop 2007,Part of the Second Life Community Convention,Chicago: WordPress,2007,pp.27-34.

[7] R.Nesson, “Virtual Worlds”, Retrieved February 15,2011, from Harvard Extension School: http://www.eecs.harvard.edu/ nesson/e4/,2007.

[8] B.Joseph,“Global Kids, inc's,Best Practices in using Virtual Worlds for Education”,Second Life Education Workshop 2007,Part of the Second Life Community Convention, Chicago:WordPress,2007,pp.7-14.

[9] P.Michels,"Universities use Second Life to teach Complex Concepts”,Retrieved January 21,2011,from http://www.govtech.com/gt/252550?topic=118264,2008.

[10] H.Mason,"Experiential Education in Second Life",Second Life Education Workshop 2007,Part of Second Life Community Convention,Chicago: WordPress, 2007,pp.14-19.

[11] D.Thomas,J.S.Brown, “Why Virtual Worlds Can Matter”,International Journal of Media and Learning,vol. 1,no.1,2009.

[12] M.D.Dickey,"Brave new (interactive) worlds:A review of the design affordances and constraints of two 3D virtual worlds as interactive learning environments", Interactive Learning Environments,vol:13,2005,pp.121137.

[13] J.Lombardi, M.P.McCahill, “Enabling Social Dimensions of Learning Through a Persistent,Unified, 
Massively Multi-User,and Self-Organizing Virtual Environment",Proceedings of the Second International Conference on Creating,Connecting and Collaborating through Computing,Washington DC:IEEE,2004,pp.166172.

[14] M.D.Icaza,"Scripting With Mono”,Retrieved January 20,2011, from Mono-Project:http://www.monoproject.com/Scripting_With_Mono,2008.

[15] D.Wood,“Experiential learning through 'real world'placements undertaken in 3D virtual world' spaces”,Same places,different spaces.Proceedings ascilite Auckland,2009.

[16] D.Butler,J.White,“A slice of Second Life: Academics,support staff and students navigating a changing landscape",Hello! Where are you in the landscape of educational technology? Proceedings ascilite Melbourne,2008.

[17] R.Elen,“Oxford University’s virtual First World War site opens in Second Life",Retrieved January 20,2011,from http://brideswell.com/content/uncategorized/oxforduniversitys-virtual-first-world-war-site-opens-in-secondlife/,2009.

[18] Scopes,J.M.Lesley,"Learning archetypes as tools of Cybergogy for a 3D educational landscape:a structure for eTeaching in Second Life", University of Southampton,School of Education,Masters Thesis,2009.

[19] D.Skiba,“Nursing Education 2.0:second life”,Nursing Education Perspectives,28,2007,pp.156-158.

[20] E.Polvinen,"Teaching Fashion in a Virtual Environment",Retrieved February 2,2011,from http://fitsl.wordpress.com/2007/12/05/elaine-polvinenteaching-fashion-in-a-virtual-environment/, 2007. 